\title{
VESICATION AND SOME VESICANTS
}

\author{
BY
}

\author{
M. W. GOLDBLATT
}

Manchester

\section{Introduction}

In recent years the incidence of dermatitis has increased enormously both in the chemical industries and in the ever widening field of other industries in which chemical compounds, particularly organic, have been applied. In the chemical industry the sequence of appearances known as dermatitis is so common that it is possible to see a great number of cases of much interest without forming a picture in the mind of more than the outward manifestations.

If one were to describe in the shortest terms the outstanding characteristic of so-called industrial dermatitis, it is almost certain that after sufficient experience one would wish to emphasize its ' nonspecificity.' No one seeing these cases frequently can fail to be impressed by the similarity of the appearances and the diversity of the exciting agents. Whilst chronic affections, including such widely different conditions as acneiform eruptions and epitheliomata, are evoked by chemical agents, the reactions to an enormous number of widely differing chemical compounds are so similar that the term 'non-specific' can justifiably be applied to them. Such eruptions are, in general, of the acute variety and receive appellations such as papular, papulovesicular, vesicular, bullous, and so on. The signs of these acute eruptions are similar to those of eczematous eruptions, erythema, macule or raised macule, papules, small or medium-sized vesicles, bullae, oedema, etc. The symptoms are irritation, itching, prickly and burning sensation, tightness. Naturally, these signs and symptoms are mixed in different proportions in different cases depending on the individual constitution, on the site of the eruption, on the degrees of contamination, on the rapidity of treatment, on the superadded injury from scratching and home treatment.

Features of this type of dermatitis are the tendencies to set up a polyvalent sensitization, to recur and to appear in parts remote from the site of the original contamination even after removal from contact. The pathology includes spongiosis, parakeratosis, acanthosis and other features associated with eczema. The changes occurring in these cases may be divided into-

(1) vascular changes,

(2) movements of fluid (oedema, vesication),

(3) cellular changes (including sensitization), and

(4) repair processes.

$\mathbf{P}$
In this paper we are concerned with the mechanism of vesication and with illustrations of it in the action of certain industrial compounds of which we have experience.

\section{Mechanism of Vesication and Blistering}

The phenomena of vesication are the common result of so many different agents that one is impelled to imagine that there must be an underlying mechanism common to all. Vesication can be produced by heat, cold and ultra-violet light; by friction; by such well-known vesicants as cantharides, chloroform, mustard oil and so on.

The action of chemical irritants, with which we are mainly concerned, is usually described as causing vascular spasm later followed by excessive dilation of the underlying vessels of the skin. This dilation brings about a great transudation of fluid. The lymphatics threading the epithelium also dilate and the prickle cells are so devitalized that rupture of the intercellular bridges follows and a vesicle forms in the epidermis (MacLeod and Muende, 1940). The accompaniments of the formation of a vesicle are progressive weakening of the prickle cells and cellular degeneration. This intra-epidermal vesiculation precedes the formation of a bulla as the exudation of fluid continues, provided the prickle bridges yield. The vascular dilation in the papillary layer is possibly in part brought about by a reflex motivated by the irritant on the sensory endings in the corium.

The location of the skin attacked by the irritant determines whether the bulla will develop within the epidermis or beneath it. This follows from the variations in mechanical resistance of the prickle layer in different parts of the integument. In the epidermis of the palms or soles the prickle layer is tough whereas on the face, flexor surfaces of the arms and legs and on the abdomen it is relatively weak. Thus, as fluid transudes from the papillary vessels it will tend to push up the whole thickness of the epidermis of the palm or sole giving rise to a bulla of which the roof is the whole epidermis and the floor the upper region of the corium. In other regions, e.g. face, dorsum of the hand, etc., the bulla will develop in the epidermis with the more or less devitalized stratum corneum and stratum granulosum as the roof and layers of the stratum malpighi as the floor. Thus are formed the thick-walled and 
thin-walled bullae of which examples will be given below. It may be helpful to recall that the thicknesses of the epidermis of the palm and soles in the adult may be about $0.8 \mathrm{~mm}$. and $1.4 \mathrm{~mm}$. respectively, whereas for the other parts mentioned above it varies between $0.07 \mathrm{~mm}$. and $0.12 \mathrm{~mm}$. (Maximow and Bloom, 1934).

The theory of Lewis (1927) is well known. He held that there is no basal distinction in the ultimate mechanism whether the eruption was that of herpes, pemphigus, bullous or any other form of vesication. The blister, he held, like the wheal is a manifest sign of increased vascular permeability. It requires no theory to tell us that when a pocket of fluid develops there must be a source of that fluid and that in the case of a blister that source must be the vascular supply of the skin. Lewis held that there arose a state of increased permeability which was part of his well-known 'triple response.' This responsein some sense a protective response-consists of three parts, dilation of the minute vessels of the skin, increased permeability of the vessels and then a dilation of the arterioles. All these effects are attributed to the release of $\mathrm{H}$-substance which in its action resembles histamine. The effects of $\mathrm{H}$ substance are limited in severity by the advent of a refractoriness in the vessels to $\mathrm{H}$-substance (the refractoriness is really tested against histamine). Thus, in the case of a wheal there appears to occur a rapid outflow of fluid from the over-permeable vessels and a rapid decline in the vascular permeability due to the onset of refractoriness. The blister, however, arises from a slow transudation and a much more gradual establishment of refractoriness so that the passage of fluid can continue until a pressure is developed sufficient to force apart the epidermal layers. It will be seen later in our description of cases that the time relations of blistering agents do in fact always point to a slow onset of the effect.

We have to ask ourselves how, if we accept Lewis's theory, the vesication comes about. First of all, the substance must penetrate the epidermis and reach living cells. In order to injure the cells there must ensue either an attack on the cells from outside or a penetration within the cells or both. To penetrate to the cell-interior the toxic agent must be water-soluble or it must undergo some metabolic change which leads to water-soluble bodies. Most vesicants are not water-soluble but in varying degree oil and fat soluble. In consequence of this property, vesicants can more or less readily penetrate to the living cells whereas water-soluble compounds cannot normally do so. This penetration is probably to be regarded as occurring through the openings of the sweat and sebaceous ducts, where conditions favourable to absorption are very different from those obtaining on the cornified layer of normal skin. But it should be kept in mind that watersoluble gases can pass into the skin, e.g. $\mathrm{HCl}$ gas. Powerful water-soluble agents attack the surface of the skin, e.g. caustics. A water-soluble compound, even in high concentrations, if pricked through the skin is rapidly diluted and diffused, whereas an oilsoluble compound will remain in concentrated form and more or less in situ.

Thus, a tentative picture of the vesicant action of an oil-soluble compound is the following:

(1) Applied to the skin, it has the possibility of penetrating to the living cell layers.

(2) Having penetrated, the concentration remains high for considerable periods.

(3) If the compound is stable, it will exert its effects by attacking the cell surfaces.

(4) If the compound is unstable in aqueous media, it may liberate water-soluble bodies which may penetrate the living cells and exert the toxic effect (cf. old theory of action of mustard gas which attributed effect to liberation of $\mathrm{HCl}$ ).

(5) By injuring the living cells, $\mathbf{H}$-substance of Lewis is liberated and this brings about the triple response.

(6) The localization of the irritant, the protracted action and the consequent maintained liberation of $\mathrm{H}$-substance give the required conditions for a gradual increase in vascular permeability and hence the much slower onset of refractoriness. Fluid, therefore, continues to exude until the epithelial layers are forced apart with formation of a vesicle or blister. (It is significant to point out that Lewis was unable to produce blisters with histamine. However, this may be due to inability to simulate a sufficiently gradual introduction of the material.)

This view of blistering is of great physiological interest but it is still, as far as we know, only a theory. Lewis himself was quite aware that there might be other factors involved and was careful not to promulgate his $\mathrm{H}$-substance as a single agent. Histamine salts, like other electrolytes, are not absorbed through the skin and do not blister. A recent case of my own is worth recording as showing that histamine can certainly penetrate to some extent, but this probably occurred through the openings of ducts.

\section{Histamine Case}

A young girl laboratory assistant, aged 16 years, darkreddish hair with fair skin, gave a personal history of sensitivity to strawberries, sticking plaster, eggs (?). She had experienced 'heat spots' on occasion. No sensitivity, however, to shell-fish. She is engaged in a laboratory where virus work is carried out but had never previously had a rash on her skin whilst working in the laboratories.

One morning, in the ordinary course of her work, she weighed out $800 \mathrm{mg}$. of histamine $\mathrm{HCl}$ and dissolved it in $10 \mathrm{ml}$. distilled water. She spilled some of the solid compound on the bench and wiped the bench with her handkerchief. She then went to the refrigerator and on her way back to the laboratory she used her handkerchief to wipe her right eye. She experienced no symptoms.

Ten minutes later a friend drew her attention to her right eye which now appeared inflamed and swollen with considerable lachrymation. There was no pain.

On examination, I found marked oedema of the right upper lid, extreme injection of the right conjunctiva and marked erythema round the orbit. Pupils were normal Left eyelids, etc., completely unaffected. Having concluded that this was a histamine reaction, no treatment was given and the girl was kept under observation. 
Five hours later the oedema of the upper lid was diminished but still present, the injection of the conjunctiva had completely disappeared, but there was slight residual erythema on the cheek and around the orbit. Next day all signs had disappeared.

\section{Comment}

There can be no doubt that this was due to histamine, the whole triple reaction being manifest. The girl showed no greater reaction to histamine applied by scratch method than did a normal control girl. The dilutions used were $(1-50) \times \frac{1}{10^{-6}}$.

The intense reaction was, in my view, due to an enormous dose rubbed into the skin with the absorption of probably a small amount.

Demonstration of histamine or histamine-like substances in the skin is not a simple matter and should not be accepted without very sceptical scrutiny. Haas (1941) reports increases in the histamine content of the skin produced by various agents, among them such vesicants as mustard oil, cantharides, capsicum, croton oil, and turpentine oil. Moss (1942) went so far as to administer histaminase to persons susceptible to Rhus toxicodendron and found that only one out of eight cases treated (45 units per os for 25 days) subsequently developed the dermatitis when camping in an area thick with the irritant plant. We are, however, not over sanguine that such prophylaxis would prevent the development of the severe blistering of powerful vesicants.

\section{Some Comments on Vesication}

As already pointed out, there is, in general, considerable delay between the contamination of the skin and the advent of pain, heat and blistering. The rapidity of onset of these signs and symptoms seems reasonably to be attributable to the speed of absorption of the vesicant and the attainment of a concentration in the skin sufficient to irritate the endings of the sensory nerves and to injure the living epidermal cells. The well-known difference in speed of absorption of Lewisite and mustard gas sufficiently explains the more rapid onset of signs and symptoms of contamination with the former. The rapidity and completeness of healing after vesication depend upon the degree to which severe damage to cellular and vascular elements in the skin occurs. Scar formation depends upon the depth to which the vesicant penetrates and the degree of injury to cellular and vascular elements. If the base of a vesicle or bulla is formed by the corium or if the papillae are exposed, scarring will follow, but this will not result if a floor of epidermal cells remains. With severe injury to subjacent layers, there is a greater susceptibility to infection and its sequelae. There may be severe blistering as judged by size and extent without subsequent scarring. Contact of skin with a vesicant when either the skin or the vesicant is at an elevated temperature permits more rapid penetration and more severe vesication. The thickness of the wall of a blister depends upon the location, e.g. blisters on the dorsum of the hand are thin-walled, those on the palms or soles are thick-walled.
The fluid in a blister is plasma and the process of coagulation can be often observed. In cases where an inflammatory reaction occurs blister fluid will contain leucocytes and other blood cells; in some cases erythrocytes may be found.

Retention of even a small dose of a vesicant in gloves worn to protect against irritants will often produce extensive vesication, whereas had no gloves been worn an equal contamination would probably have been removed by wiping or washing. The condition of the skin inside a rubber glove is favourable to maximal effects from a vesicant or generally dermatitic agent.

Vesicants in industry are only rarely successfully inactivated in time to prevent the reaction of the skin. In the rare cases where pain is rapidly experienced (e.g. dichlor chlor-vinyl arsine) or where the contamination is observed immediately, it is possible to inhibit penetration by inactivating agents.

The process of blister formation may be regarded as in some sense protective, serving to dilute the vesicant and to prevent its further penetration. A competition may be envisaged between the penetrating vesicant inwards and the out-pouring of fluid from the over-permeable vessels. In spite of vesication from highly toxic substances, systemic symptoms do not in general appear. The possibility of systemic poisoning from arsenical vesicants has been emphasized in various publications (e.g. Medical Manual of Chemical Warfare, H.M.S.O., 1940) and theoretically this is reasonable. In the several cases of vesication due to arsenical vesicants which we have observed (vide infra) there have not been systemic symptoms but, nevertheless, the recommendation as to evacuation of arsenical bullae should be adhered to.

\section{Treatment of Vesication}

The appearance of severe vesication may give rise to considerable anxiety both in the patient and in the industrial doctor. The tendency is to interfere too much. If the blisters are left intact, the time comes when the enclosed fluid begins to seep through minute perforations in the epidermis. So long as the increased permeability of subjacent vessels or the inflammatory process continues fluid will be released. If the area involved is very great as in severe and extensive burns or scalds, this continued loss of fluid has its well-known consequences. In the vesication usually met with in industry the areas involved are not extensive and hence systemic effects are not likely to occur from the mere loss of fluid.

The procedure followed in dealing with the blistered skin is that applied in the case of burns and the simpler the method the better and the quicker the results. The first thing to realize is that, whatever the cause of the blistering, the tissue affected is considerably or completely devitalized and hence is more liable to infection than is normal tissue. Secondly, the contents of the blister offer a rich nidus for the growth of organisms. If, as was usual in our many cases, the blistered skin is 
seen before spontaneous oozing of fluid begins, the first thing to do is to take measures to sterilize the skin surface. The difficulty of achieving this is amply dealt with by Colebrook (1944). In industrial conditions the maintenance of bacteriological cleanliness in the strict sense is probably not attainable. On the other hand, maintenance of freedom from pyogenic organisms is not only attainable but is essential for efficient industrial practice. The criterion of all good industrial medical practice is the rapidity with which workers are returned to work in a fully restored condition. In the case of vesication the absence in general of maintained subjective symptoms permits of the uncomplicated application of sound methods for assuring a bacteriologically healthy condition. The examination of the affected parts can be made without any handling, but if handling is considered necessary the nurse or medical officer should scrub up with as much care as would be considered necessary for an open wound.

Since, substantially, the vesicant action is of the nature of a second degree burn, it is relevant to quote Logie (1944): ' The second degree burn heals well with many and varied applications provided they do not offend surgical principles ....'

The work of Colebrook has shown that the 'resident flora' of the skin (staphylococci and diphtheroid) cannot be eradicated by the ordinary use of soap and water or by the common chemical agents used for this purpose (alcohol, iodine, mercury salts, hypochlorites, etc.) since none of them appears to be able to reach the organisms in the depths of the sebaceous glands and hair follicles.

Our practice is to clean the skin with soap and water or surgical spirit to remove superficial contaminations, being careful not to break the blisters if thin-walled. If the skin is contaminated with oil, grease, chemical compounds, suitable solvents may be required to remove them as, for example, trichlorethylene or sulphonated vegetable oils for oils and greases, benzol or acetone for certain organic intermediates. Where thick-walled blisters are present there is less likelihood of breaking them in the early stages. The skin is now dried with sterile gauze. The area is now treated with $0 \cdot 1$ per cent. acriflavine or 1 per cent. cetavlon (trimethylcetyl ammonium bromide). All recent evidence is in favour of the latter preparation as a skin disinfectant, the combination of its detergent and antibacterial properties being happy. Not much advantage is to be expected from actually washing the skin with an aqueous solution of acriflavine, but washing with cetavlon gives a valuable soap action and by leaving the solution to dry on the skin organisms are prevented from growing in the fluid later discharged from the blister. Cetavlon is a protein precipitant and hence it might have been expected that in the presence of serum there would be considerable loss of anti-bacterial properties, but Colebrook considers that significant anti-bacterial properties remain in spite of this fact.

The skin being cleansed, the next step depends upon the nature of the blister. If there are several large thin-walled blisters it is our practice to evacuate them with a hypodermic syringe to collect the blister fluid for analysis if the presence of the vesicant or its derivatives is to be determined; otherwise the blister is incised at several points to permit free drainage. The wall of the blister is allowed to collapse upon the subjacent tissue and is not cut away. The whole blistered area is now covered with sulphonamide tulle and bandaged firmly. Small blisters are not interfered with. The bandage is left in situ for at least 2 days before examination and change of dressing.

In the case of thick-walled blisters we prefer not to drain since the likelihood of introducing organisms from the skin surface appears to us greater. After washing and, as far as may be, sterilizing the skin, a sulphonamide tulle dressing and a firm bandage are applied and left in situ for 2 days.

The healing of the thin-walled blister with replacement by healthy epithelium is relatively rapid and clean. The thick-walled multiple blisters, on the palm of the hand for example, are followed in a few days by massive cracking of thick skin and pain and discomfort on extension of fingers. There is considerable brown discoloration with wrinkling of the devitalized skin. The regenerating skin seen in the fissures of the cracked and separating skin is pink and tender. At this stage we allow spontaneous separation to proceed and apply sterile olive oil or a bland ointment (e.g. boroseptic ointment, P. D. \& Co.) with comfortable bandage.

During the stage of separation of thick blistered skin, especially on the palms, stretching of the skin frequently leads to slight bleeding at the raised edges of the cracks. When this occurs over extensive areas it is desirable to swab them with cetavlon before applying the bland dressing.

The final healing of an area of thick-walled blisters, in general, requires weeks of treatment and care. In the cases we have had to deal with, chemical agents were the cause and the patients engaged in chemical work. Although we have in some milder cases permitted continuance of work with added precaution, the better rule is always to remove the case from work until final healing has occurred. In the organic chemical industry, particularly, the establishment of a polyvalent sensitivity from even slight contamination of the healing skin must be guarded against and, hence, the patient must be kept away from work. After the healing process is satisfactorily completed it must still be remembered that great precaution is necessary after return to work with organic compounds.

\section{Clinical Investigations}

The following cases give a description of vesication and present features of interest to medical personnel engaged in the chemical industry, not only because they are intrinsically significant as illustrating the effects of a variety of compounds but also because they serve to emphasize various ways in which skin injuries arise and the need to practice constant vigilance if such are to be avoided. 
The vesicant compounds, the action of which is dealt with here, arise in certain organic manufacture, in agriculture, in intermediate stages of studies on war gases and comprise the following:
A. Derivatives of pyrimidine.
B. Derivatives of alkyl sulphides.
C. Derivatives of arsine.
D. Organic mercury compounds.
E. Organic isothiocyanates.

\section{A. Derivatives of Pyrimidine}

Pyrimidine is a stable, well-crystallized compound, soluble in water giving a neutral solution. Melting point of pyrimidine is $22^{\circ} \mathrm{C}$. and boiling point $124^{\circ} \mathrm{C}$. It forms salts with acids.

The structure of pyrimidine is represented by the formula

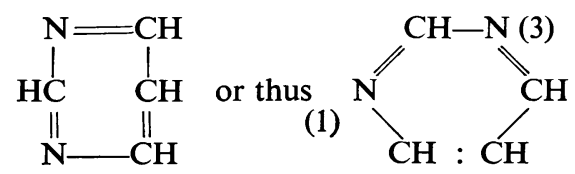

the nitrogen atoms being numbered as shown.

The pyrimidine ring will be familiar as being present in uric acid and purine derivatives, the parent compound, purine, being<smiles>Nc1cncnc1N</smiles>

a cyclic diureide derived from a hydroxy dibasic acid and urea.

The identity of the carbon-nitrogen ring of pyrimidine with that of barbiturates will also be recognized: barbituric acid is<smiles>O=C1CNC(=O)C1</smiles>

The first vesicant to be dealt with here is the trichloro derivative of pyrimidine-2.4.6-trichloropyrimidine,<smiles>ClC1=N[C@H](Cl)C(Cl)=N1</smiles>

This compound distils as a colourless liquid which solidifies at room temperature, contains 58.04 per cent. $\mathrm{Cl}$ and is volatile, lachrymatory and lungirritant.

Case 1. M. P., girl laboratory assistant, aged 17 years, fair skin and hair.

1 st contact. Engaged in distilling this compound, she spilled one or two drops on her hands. She immediately felt a burning sensation between the fingers and the affected areas developed some reddening which, however, was not very marked.

Vesication was found the next day on the 2 nd, 3rd and 4th fingers of the left hand. Having been dressed at home with zinc ointment, the blistered areas were rendered septic.

Treated on 3rd day after accident in the factory medical department by cleansing, acriflavine and a dressing of sulphanilamide tulle; observation and redressing daily led to healing and recovery in 24 days from date of contact.

2 d contact. Fifty-one days after the complete healing of blisters, this girl was again engaged in distilling the same compound. No contact with the liquid occurred but a small amount of vapour escaped which did not produce irritation of eyes, nose, or throat. In the evening of the same day, i.e. some 9 hours after the distillation, she noticed an eruption on the hands.

When examined next day, there were a small vesicular eruption on the hands, a large bulla on one thumb and a group of vesicles on the forehead where some crusting had also occurred.

Treatment and healing were straightforward and uneventful.

The case was of interest not only because of the vesicant action of the compound but because the concentration of the vapour at the second contact was too low to affect chemists working in the same region. It would seem tentatively reasonable to consider that the young woman had developed a hypersensitivity for she certainly had been exposed to at least equal concentration on previous occasions without any reaction. Further, the concentration had been too low to lead to lachrymatory effects. The distribution of the lesions due to the vapour was also much more extensive than a small escape of vapour would normally produce.

Cases of an acquired hypersensitivity after an initial attack from a direct irritant are very common in the organic chemical industry and serve to emphasize the need to take special precautions afterwards.

Case 2. M. D., lady chemist, aged 24 years, light brunette, sensitive to elastoplast.

1 st contact. This chemist had worked on pyrimidines in general and not specially with the chloro-compounds. Three months prior to the second contact (vide infra) she had prepared 2S-methyl-4-chloro-6-methyl pyrimidine,<smiles>CSc1ncc(Cl)c(Cl)n1</smiles>

This compound is a volatile lachrymator and contains 20.3 per cent. $\mathrm{Cl}$. Whilst distilling the compound some vapour emerged and produced on the face a mild eruption which she considered too mild to report; it disappeared in a week with mild treatment.

2 nd contact. On this occasion, three months after the first eruption, she performed an ether extraction of 2.4.6.trichloro-pyrimidine by shaking in a large flask (5 litres). She wore rubber gloves. The precise manner of contamination during this clumsy operation is not clear but within one hour from its completion she noticed a slight soreness on the palm of the right hand but continued working. Some four hours later pain and reddening had become marked on the palm and on the dorsa of some fingers. For almost two days she applied calamine lotion without relief until there was found on examination to be an extensive area of erythema and vesication on the hypothenar area, wrist, ulnar region of the palm and the dorsa of all the fingers of the right hand; there was now also small areas of vesication on three fingers of the left hand.

Treatment on the lines described continued for 11 days after which an extensive sharply demarcated area of thick palmar skin became detached with the subjacent tissue red and inflamed. No irritation of any kind was felt at this stage. The condition on the left hand was now quiescent.

Subsequent course was uneventful and there was substantial recovery in about a month from the onset.

From this case it is clear that the thio-chloro-methyl 
compound vapour is an irritant, that rubber gloves did not adequately protect against the trichloro-compound, that there was a very long delay in the onset of vesication (almost 2 days) preceded by early pain and erythema. In the early stages the condition could well have been mistaken for an acute dermatitis; the pain, however, was a clear indication that deeper structures than the epidermis had been reached and that vesication was to be expected.

Case 3. G. M., laboratory assistant, aged 19 years, remarkably unreactive to known powerful dermatitic agents. Engaged in the preparation of 2.4.6.trichloropyrimidine, the product being extracted with ether, dried and distilled. His laboratory girl was stated to have developed blistering on the fingers after washing up apparatus used in this process.

1 st contact. Some 3 to 4 weeks prior to the 2 nd contact he observed the development of blisters on his fingers after handling material given to him by another assistant. This was followed by another attack some 10 days later, but the process of healing was satisfactory and he recommenced work.

2 nd contact. Restarting other work with added precaution he soon developed irritant red patches on the knuckles and fingers.

On examination the appearance was that of erythematous, macular patches and no oedema, papules or vesicles were seen; there were still remains of the blistering vesicle on the web of the index and middle fingers. In the following days the eruption changed to papulovesicles with great itching.

Treatment was mainly with Lassar's paste and after a week recovery was sufficient to warrant return to work with instruction on special precautions required.

The interest in this case lay in the fact that the initial blistering was followed by a reaction of the kind common in the organic industry and brought about by many compounds. As already stated this boy was formerly remarkably resistant to known irritants and hence we conclude that a measure of polyvalent hypersensitivity was established as a result of the vesicant action of the trichloro-pyrimidine.

To summarize, the following can be stated:

(1) Trichloro-pyrimidine is a powerful vesicant.

(2) The vesication is followed after healing by the establishment of multiple sensitivities even in persons normally very resistant.

(3) $2 \mathrm{~S}$ - methyl - 4 - chloro - 6 - methyl pyrimidine vapour is a skin irritant, its action being reasonably attributable not only to its being a chloro-pyrimidine but also to its properties as a dialkyl sulphide.

The interest in a series like this attributable without any dubiety to a single compound is to discover what radicle or group is responsible.

Such derivatives of pyrimidine as 2.6.dimethyl-4amino pyrimidine are strong bases. The basicity here is due to the presence of the $\mathrm{NH}_{2}$ group,<smiles></smiles>

and the attack on the skin is similar to that seen with such a compound as hexamethylene diamine $\mathrm{NH}_{2}-\left(\mathrm{CH}_{2}\right)_{6}-\mathrm{NH}_{2}$ and is due to the alkaline properties.

But in the case of 2.4.6.trichlor compound, the action on the skin is not due to causticity. As in the case of mustard gas or Lewisite, it is the chemical structure which is responsible. In mustard we have the structure $\mathrm{Cl}-\mathrm{CH}_{2}-\mathrm{CH}_{2}-\mathrm{S}-\mathrm{CH}_{2}-\mathrm{CH}_{2}-\mathrm{Cl}$. In Lewisite we have<smiles>Cl[Hg]Cl</smiles>

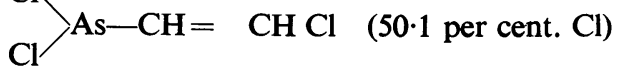<smiles>ClC(Cl)C=C[As](Cl)C=C[As]</smiles>

and

$$
\begin{aligned}
\mathrm{CH} & =\mathrm{CH} \mathrm{Cl} \\
\mathrm{As}-\mathrm{CH} & =\mathrm{CH} \mathrm{Cl} \quad(41.04 \text { per cent. } \mathrm{Cl}) \\
\mathrm{CH} & =\mathrm{CH} \mathrm{Cl}
\end{aligned}
$$

In this arsenical series the intensity of action on the skin increases with chlorination. The elements As, N, P are in the same group of the Periodic Table and hence we should expect similar properties of the chlor-vinyl derivatives.

In trichloro-pyrimidine we have the group<smiles>ClC=CC(Cl)Cl</smiles>

Looked at in this way and having regard to similar solubilities in organic solvents, it is not surprising that both di- and trichloro-pyrimidine are powerful vesicants. The severity is not so great in the case of the cyclical pyrimidine compound. A compound of the type<smiles>CC(Cl)(Cl)NC(Cl)(Cl)NC(C)(Cl)Cl</smiles>

might be expected to have very severe effects.

It is relevant here to examine a compound of very great toxicity (M.L.D. for mice- $5 \mathrm{mg}$. $/ \mathrm{kg}$.), cyanuric chloride

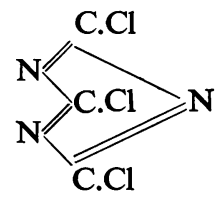

usually written<smiles>ClC1=NC(Cl)C2([Br+])C(Cl)NC2N1</smiles>

The only difference between this compound and 2.4.6.trichloro-pyrimidine is that the nitrogen atom in the 5 position is replaced in the latter by $\mathrm{CH}$. Cyanuric chloride is also a lachrymator and an irritant to the eyes and nose. We have only had one case in which the vapour of this compound emitted during weighing it out was sufficient to produce a rash on the neck and behind the ears with irritation in a laboratory assistant (fair haired and with marked acne). There seems little doubt that closer contact with this compound would produce marked vesication. 
FIg. 1.-Case 4. Vesication produced by n-butyl-b-chlorethyl sulphide. Left wrist affected.

Right wrist unaffected.

FIG. 2.- Case 4. Left wristextension from previously blistered area after exposure to sunlight. Right wristoedematous, erythematous area after exposure to sunlight ; area protected by wrist-strap pale. 9 days after Fig. 1.

Fig. 3.-Case 4. Left wrist and forearm-red with surrounding brown discoloration. Right wrist and forearm-eruption wrist and forearm-eruption
after exposure to sunlight. 28 days after Fig. 2. 


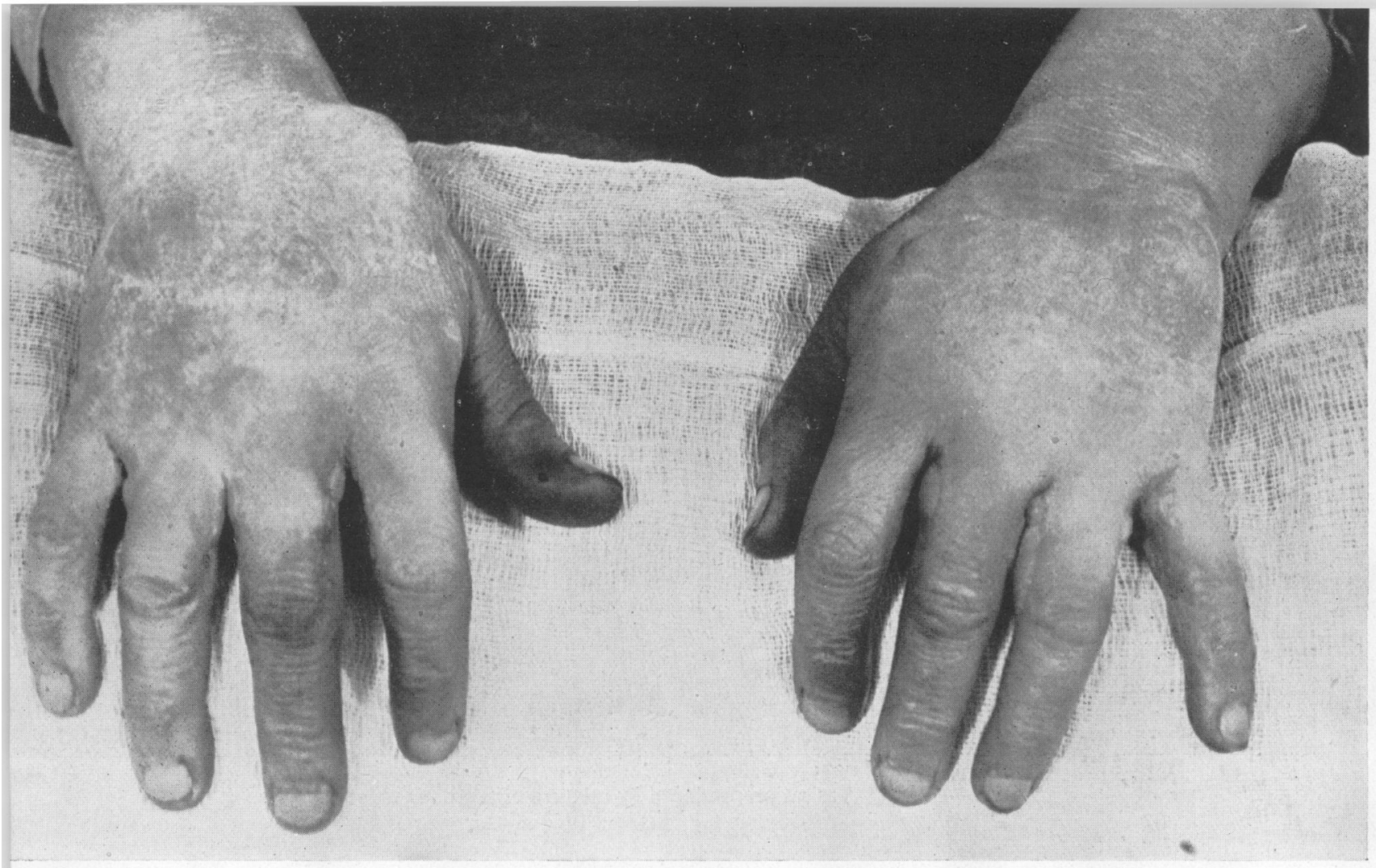

FIG. 9.-Case 15. Vesication produced by phenyl mercuric acetate."

Fig. 10 (below).-Case 16. Vesication produced by ethyl mercuric phosphate.

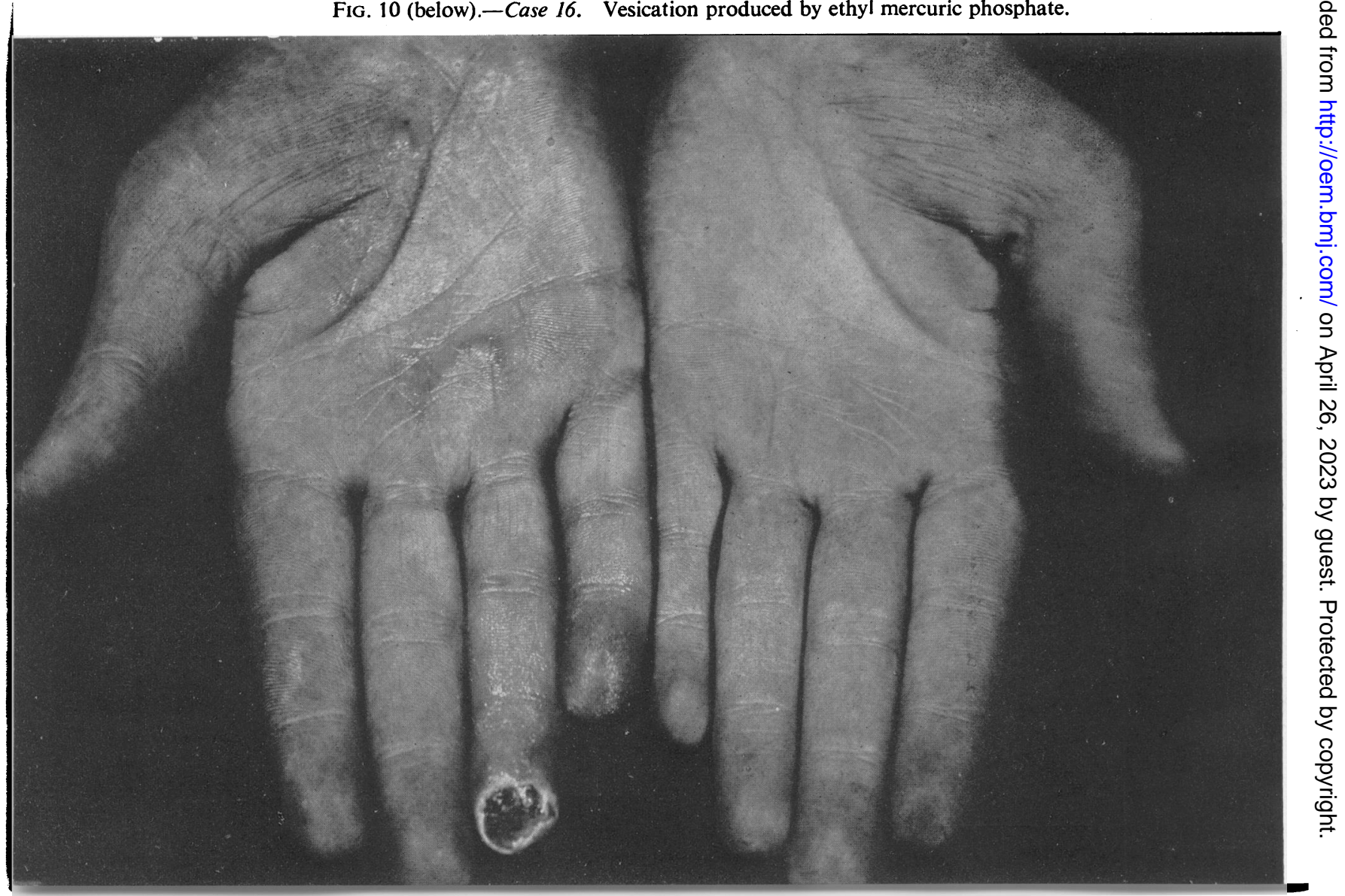




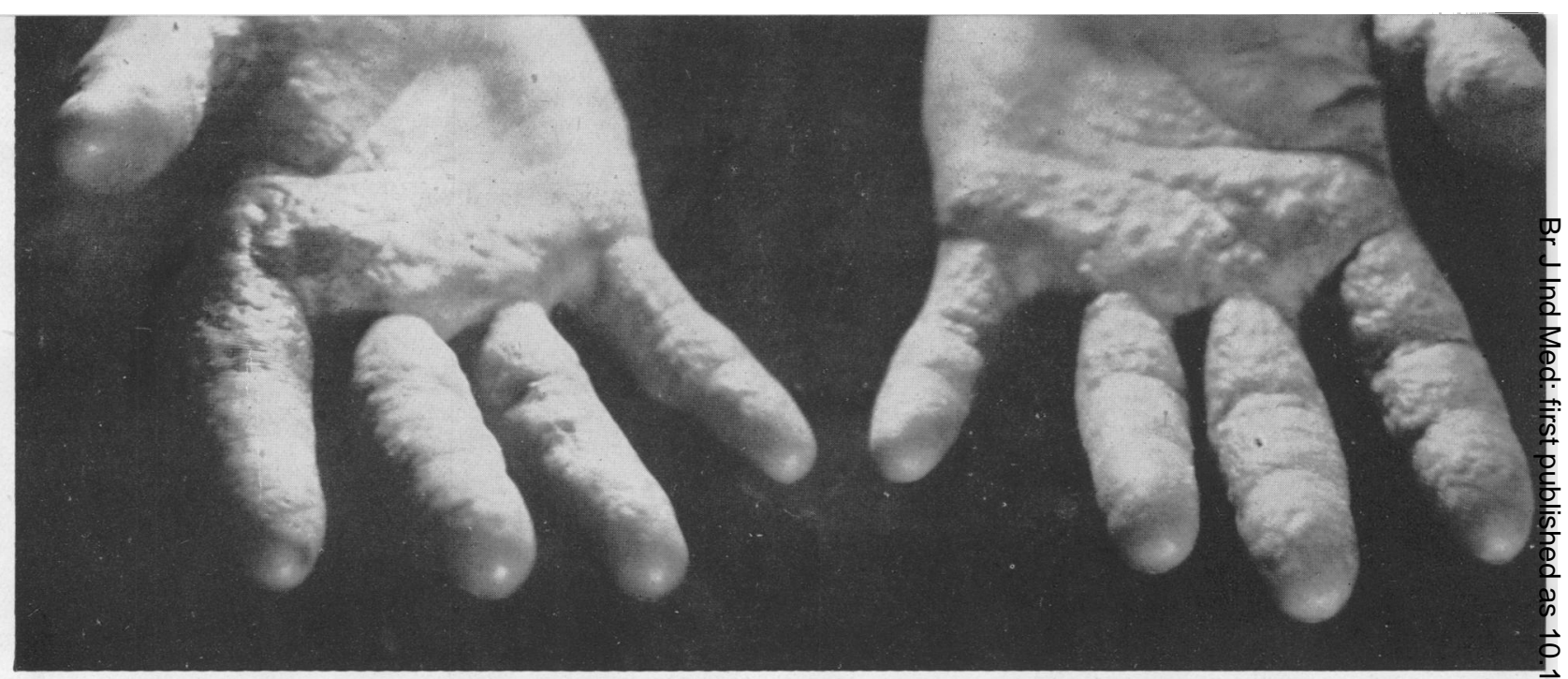

Fig. 11.-Case 17. Intense vesication produced by methyl thioisocyanate-later followed by complete denuding of palmar skin of both hands.

FIG. 12.-Case 18. Unusual case of vesication after intimate and protracted contract with solution of benzoin in benzene.

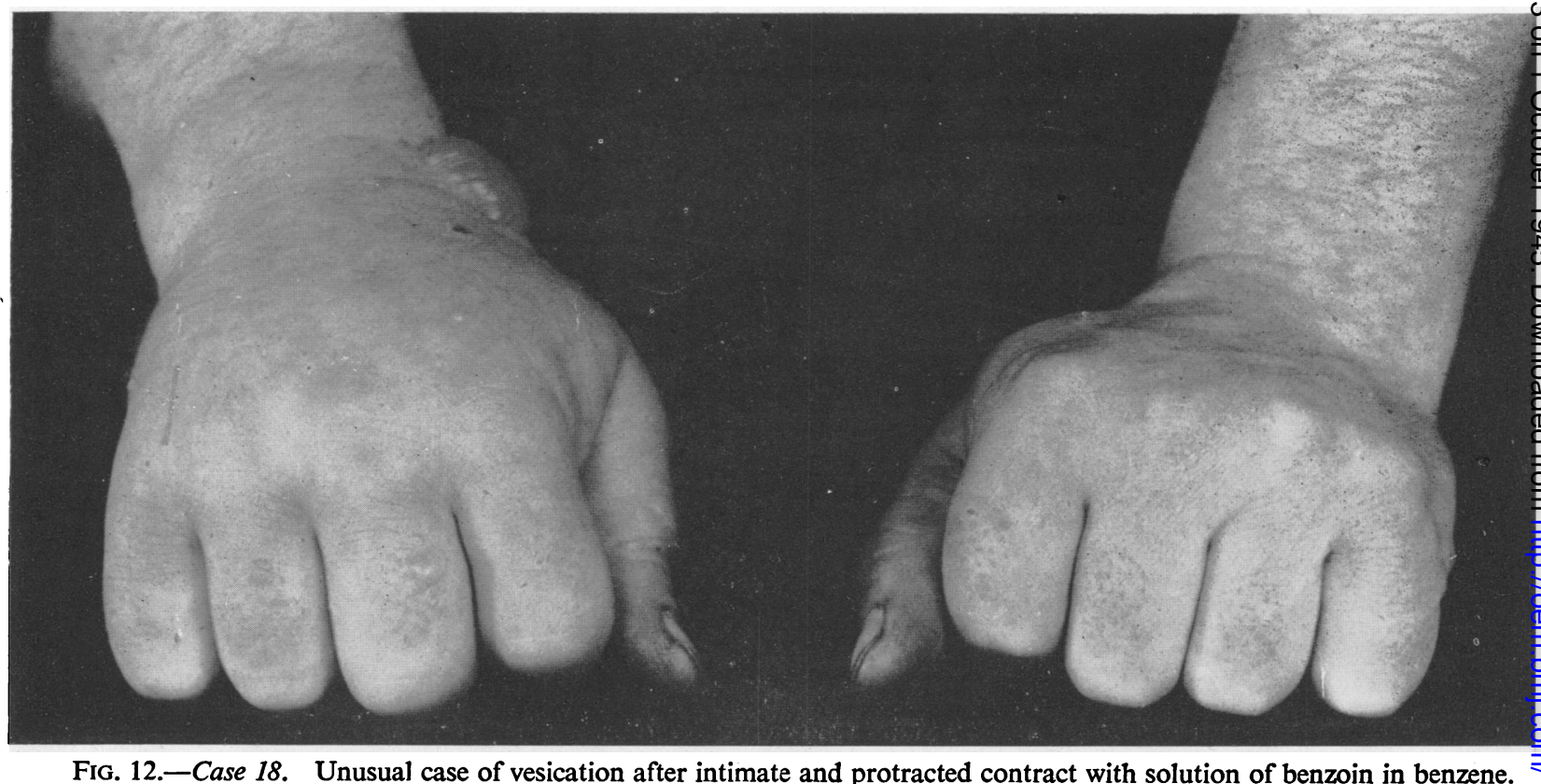

FIG. 13 (below).-Case 18. Tense plasma-filled bullae-area protected by wrist-strap pale and unaffected.

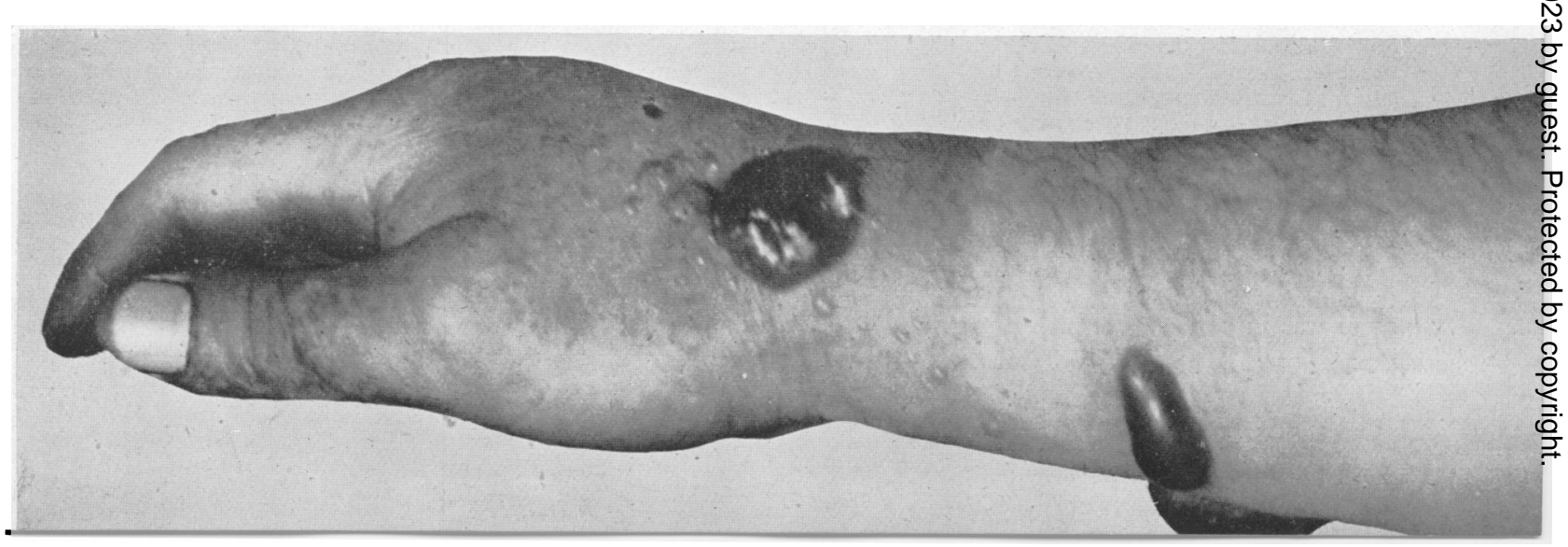




\section{B. Derivatives of Alkyl Sulphides}

The importance of chlorine as an element which in the organic series can bring about an enormous increase in irritant properties is well known. The example of the chlorinated hydrocarbons will come to mind, e.g. chlornaphthalenes and chlorinated diphenyl. The increase in irritation which follows the introduction of 2 atoms of chlorine into the $\beta$ positions in diethyl sulphide is well known. But it is always to be remembered that $\left(\mathrm{C}_{2} \mathrm{H}_{5}\right)_{2} \mathrm{~S}$ is itself an irritant, as indeed are all compounds of type

$$
\left.\mathbf{R}^{\mathbf{R}}\right\rangle \mathbf{S}
$$

where $\mathbf{R}, \mathbf{R}^{\mathbf{1}}=$ alkyl radicles, inorganic elements or aromatic radicles. We recently had opportunity to observe closely the irritant effects of a compound resembling mustard gas in structure, viz. n-butyl-bchlorethyl sulphide-<smiles>CCSCCCl</smiles>

This compound contains a little more than half the weight of chlorine per molecule than does mustard gas (23.3 to $44 \cdot 7)$. In spite of this, as we shall see, the vesicant action is extremely powerful.

$$
\mathrm{S}\left\langle\begin{array}{l}
\mathrm{N} \text {-butyl-b-chlorethyl sulphide } \\
\mathrm{CH}_{2} \mathrm{CH}_{2} \mathrm{Cl} \\
\mathrm{C}_{4} \mathrm{H}_{9}
\end{array}\right.
$$

Liquid, sp.gr. 1.01, rather pleasant odour, b.p. about $92^{\circ} \mathrm{C}$. at $30 \mathrm{~mm}$. $\mathrm{Hg}$.

Case 4. A chemist, H., aged 22 years, was engaged in the preparation of this compound and certain oxidized derivatives. Having prepared the compound, he vacuum distilled $133 \mathrm{~g}$. of it, placed it in a flask for $\frac{1}{2}$ hour and then transferred it to another reaction flask where it was heated with glacial acetic acid and hydrogen peroxide. A chemist nearby complained of his eyes at this time but $\mathrm{H}$. was not disturbed by the vapour.

That evening at home he noticed a small blister on a red patch on the flexor surface of his left wrist, where he normally wears a wrist strap and watch.

At 2 a.m. that night he found 2 large blisters in the region corresponding exactly to the position of the wrist strap (fig. 1). The pain of the lesion awakened him. The blisters were tense with yellow fluid and were surrounded by reddened skin.

After examination and photograph, blister fluid was removed by hypodermic needle. The epithelium was allowed to remain in situ and affected area dressed with sulphanilamide tulle. Progress was satisfactory and uneventful. The area was examined and dressed daily. Patient was taken off work.

Nine days later the affected area was denuded of epithelium and surrounded by a brown-red area. During the preceding 2-3 days, patient had been much in the sun and became very sunburnt. He had also, on instruction, treated the wrist strap with bleach; after drying he had put it on the other wrist.

Condition now was:

(1) Left forearm-extending from the previously blistered area there was now a linear, red, slightly raised serpiginious area which was not irritating.

(2) Right forearm - flexor surface - red, hard, oedematous rectangular area above a pale area where wrist strap was in contact, i.e. area not exposed to sun was pale (fig. 2).
Treatment and progress were uninterrupted and uneventful.

Twenty-eight days later the patient stated that he had a sun-bath in his garden and, after about 3 hours exposure to hot sun without his shirt on, he noticed a red rash consisting of separate spots on his right forearm. flexor surface, extending from the middle of the forearm to above the elbow; there was some itching. The spots became confluent that night and on the following day there appeared a slightly raised pink eruption with some papule formation but no vesiculation. No other eruption elsewhere except slightly on the wrist. Originally affected area of the left wrist (vide supra) was now pink with brown discoloration surrounding it (fig. 3).

This case shows several of the characteristic features of the sequelae of contamination with compounds of the chlor-alkyl sulphide class as follows:

(1) N-butyl-b-chlor-ethyl sulphide is a powerful vesicant showing time relations of effects similar to those of mustard gas.

(2) It can slowly penetrate leather.

(3) A small amount of irritant material remaining after treatment of the leather strap with bleach set up an inflammatory reaction on normal skin.

(4) After substantial healing of the blistered area, there remained a marked photosensitivity.

Contamination of the skin by penetration through a wrist strap is unusual, but among workers it not infrequently happens through fabric or leather gloves or through defective rubber gloves. The lesson is obvious.

$$
\begin{aligned}
& B \text {-chloro-ethyl-methyl sulphide } \\
& \mathrm{S}\left\langle\mathrm{CH}_{2} \mathrm{CH}_{2} \mathrm{Cl}\right. \text { (32.1 per cent. Cl) }
\end{aligned}
$$

This compound by virtue of its lower molecular weight contains a much higher proportion of chlorine than the n-butyl compound.

Case 5. H. F., undergraduate chemist, aged $19 \frac{1}{2}$ years, was engaged in the preparation of vinyl sulphones. His chemist was handling b-chloro-ethyl-methyl sulphide wearing rubber gloves.

At between 10 and 11 a.m. one morning, H. F. inadvertently touched his chemist's rubber glove and a drop of the above compound remained on the extensor surface of the right thumb. The drop of liquid was washed from the skin some little time later.

About 5 hours later H. F. observed a small patch of redress on the skin but was not discomforted. His chemist advised him at this stage to put bleach on it; this he did and allowed the bleach to dry on the skin.

Some 12 hours after the contamination 2 closely lying small blisters appeared on an erythematous base. The blisters coalesced about 14 hours after the contamination and there was some pain on stretching the skin.

Four days of treatment on lines outlined found the blistered area clean and led to uninterrupted recovery.

In the crowded conditions of war-time, events of this kind have not been infrequent, chemists and others being affected by materials with which they were not concerned.

It is not easy from this case to state whether the compound involved was more or less violent a vesicant than the n-butyl compound. The effect of the contamination was very local and bore out the view that the oil-soluble vesicants remain locally concentrated until, presumably, inactivation takes place. The time relations of the blistering process were again similar to those of mustard gas.

\section{Derivatives of Arsine}

As, fortunately, there has not been any gas warfare in the recent war, opportunity to see the effects of various types of war vesicants has not been afforded. Nevertheless, much research went on from 1940 on this kind of substance. 
The arsenical smokes received a good deal of attention, in particular the aromatic arsenical cyanides. The study of intermediate stages in the manufacture of these and later the production of these intermediates in bulk came within our sphere of control. It may be mentioned in passing that in the course of this investigation (2-3 years) many tons of $\mathrm{As}_{2} \mathrm{O}_{3}$ passed through the shed specially allocated for this work. Regular medical examination of the workers was instituted and, considering the rather crude manufacturing methods used, it was a source of no little surprise that no cases were discovered. After a few months of manufacture we sketched a method of handling (or rather non-handling) of the arsenic which was quickly installed and perhaps contributed to the complete absence of any case of arsenical poisoning throughout the 3 years work. The final products, $\mathrm{C}_{6} \mathrm{H}_{5}$. As : $\mathrm{Cl}_{2}$ and $\mathrm{C}_{6} \mathrm{H}_{5}$. As : $\mathrm{O}$, were handled in the plant in such a way that no cases of skin injury were met with among the workers. But on the research side cases were found among the chemists and we propose here to give an outline of the phenomena observed.

Phenyl arsine dichloride. $\mathrm{C}_{6} \mathrm{H}_{5} \mathrm{AsCl}_{2}$ (M.A.).

Case 6. R. S. N., chemist, aged 26 years, fair type; as a child he had attacks of urticaria and was subject every year to hay-fever.

Whilst working on the preparation of M.A. a small liquid contamination occurred on the right forearm; this led in a short time to erythema and a few small vesicles appeared here and on a finger of the left hand. Continuing at work small serous vesicles appeared on the right temple.

In order to observe the development of these lesions no treatment was given and he continued at work with, however, added precautions. On the fifth day from the first contamination a crop of vesicles on a red base was present on the forehead and nose and erythema had spread to the flexure of the right arm with multiple vesicles on the forearm (figs. 4 and 5). The point of original contamination on the right forearm now showed a puckered central area surrounded by a red area sown with minute vesicles (fig. 6). Local irritation was slight but greatly aggravated in bed. On the following day there was a spread of vesication round the site of the original contamination and of erythema to the back of the neck. Treatment was now commenced with Lassar's paste and Veganin, the patient being put to bed as he had developed a cold.

During the next 12 days there was, in spite of removal from all possible contact, spread of vesication preceded by development of erythema until on the 19th day all areas had practically completely recovered, a fine desquamation of most areas continuing for some days. In the later stages dressings of oil and calamine were used.

Reviewing this case we may note the rapid vesication following the original contamination and the great spread that took place due, doubtless, to continuance at work in low concentrations of vapour. Sensitivity to such concentrations was certainly increased by the establishment of the original lesion. It is to be noted also that new crops of vesicles occurred after removal from exposure which suggests a measure of generalized sensitization.

About a month after the first vesication above, the patient was working with diphenyl chlor arsine, $\left(\mathrm{C}_{6} \mathrm{H}_{5}\right)_{2} \mathrm{AsCl}$ (D.A.), and a splash of liquid occurred on to his left forearm. It was immediately treated with sodium hypochlorite but, nevertheless, in some 10-15 minutes irritation began and a flare of erythema appeared from elbow to wrist on the ulnar aspect. Itching and erythema continued for 4 days when vesicles began to develop on the reddened area. On the 5th day the erythema had been replaced by groups of small vesicles located mainly round the hair follicles. There was no irritation at this stage and recovery took place after about 12 days. Considering that inactivation by hypochlorite was immediate we must consider that the speed of penetration was very great and that D.A., left in situ, would produce severe results.

Phenyl arsine dichloride and diphenyl arsine chloride.

Case 7. D. S. P., chemist, aged 24 years, dark hair and skin, skin rather dry. This man was engaged with a variety of arsenical compounds and at the time of the events described below was handling the following 4 compounds: $\mathrm{C}_{6} \mathrm{H}_{5} \mathrm{AsCl}_{2}, \mathrm{C}_{6} \mathrm{H}_{5} . \mathrm{AsO},\left(\mathrm{C}_{6} \mathrm{H}_{5}\right)_{2} \mathrm{As} \mathrm{Cl}$, $\left(\mathrm{C}_{6} \mathrm{H}_{5}\right)_{3}$ As.

In spite of having had his hands, wrists and lower forearm protected with rubber gloves, contamination by one or more of these compounds occurred.

It will be simple to visualize the sequence by tabulating the appearances on succeeding days.

Day

1 Experiment performed but no ill-effects noted.

2 He observed slight redness and itchiness on right wrist.

3 Right wrist began to swell but there were no vesicles.

4 Confluent masses of vesicles appeared on right forearm and wrist and vesicles on red base on dorsum of right hand. One medium-sized vesicle surrounded a white raised rim on a reddened base appeared. The left forearm and wrist were similarly but less severely affected. Some of the vesicles had already broken down and small cracks were left in the skin. On the face there was a circumoral somewhat itching papular eruption. Patient was removed from all exposure.

5 Erythematous area extended with vesication on right wrist; half-inch blister with large number of minute and small vesicles around it. Similar development to medium-sized vesicles on dorsum of right hand. On left hand and wrist erythema with slight development to vesiculation. Face and chin, no further development.

6 Oedema of right forearm with increase in vesiculation. On left forearm large blister just above dorsal wrist, surrounded by raised pale area in turn surrounded by ring of small vesicles (fig. 7). Right leg now showed patch of erythema halfway down from the knee on tibial surface.

8 Marked further development of vesication on dorsa of both hands and on flexor wrists. Oedema of both forearms (fig. 8). Supratrochlear glands enlarged on both sides. No great discomfort. Patch on leg not further developed.

9 Vesication still marked by improving. Some extension to flexures of both arms. Supratrochlear gland on left arm larger. Oedema still present.

10 Great improvement. Glands still palpable but diminished in size.

18 Dorsa of hands and wrists show red, roughened, cracking, inflamed skin but there are no subjective symptoms.

22 Substantially recovered. Treatment on lines given. For the face, always a difficult problem in industry, the treatment was liq. alum. acetat. after cleansing; no covering was used.

The precise manner in which the original contamination came about was not discovered. There is a good deal to be said in favour of doing work of this kind without gloves: arrangements for plunging the hands or arms straight into a bath of inactivating solution immediately a drop of any material being handled alights on the skin being more likely to preclude the effects of contamination unperceived if gloves are worn. 
We cannot judge as to the amount of material which contaminated the skin, but from the long delay before the first signs or symptoms appeared we conclude that the subsequent severe effects were due to the establishment of hypersensitivity to the low concentrations of vapour which are almost inevitable in work of this kind.

The development of blistering after removal from exposure, remote from the point of original contamination (probably right wrist) must indicate a wide dissemination of the irritant or a derivative of it or conceivably the release of some locally formed allergen. The patch on the right leg suggests that, had work been allowed to continue, there would have arisen a very widely distributed affection.

The enlargement of the supratrochlear glands is, in our experience, an unusual accompaniment of even very severe dermatitis or vesication, provided, as in this case, there is no sepsis.

We regard this case as one of vesication from a mixture of arsenical vesicants with a secondary sensitization.

Case 8. F. R. C., chemist, aged 29 years, dark skin and hair, no history of sensitivities. Engaged in the analysis of the ' mixed oil ' $-\mathrm{C}_{6} \mathrm{H}_{5} \mathrm{AsCl}_{2}+\mathrm{C}_{6} \mathrm{H}_{5}$.As.O.

During some 3 weeks of work of this kind this man experienced no more than slight irritation and reddening of the face from which there was no further development.

One morning, without any warning or knowledge of contamination, he observed a single blister, 3-4 $\mathrm{mm}$. in diameter, on a slightly reddened base. This was situated $2 \frac{1}{2}$ inches above the wrist on the left flexor forearm. There was no irritation. We opened the blister, removed the skin and dressed with $1 / 3000 \mathrm{KMnO}_{4}$. In spite of no spread or complication the lesion did not heal for over a month at which time there was still an erythematous patch with a central scab.

We mention this case to illustrate how long a time even an apparently trivial lesion due to organic arsenicals can take to heal.

Reviewing these and other cases of arsenical vesicants, we find it difficult to conclude as to which of them is the most potent. The dichloro compound contains 31.8 per cent. $\mathrm{Cl}$ and the monochloro 13.4 per cent. $\mathrm{Cl}$, but this is not a sufficient criterion as to vesicant properties. As we shall see, other chlorinated organo-metallic compounds possess vesicant properties and the latter certainly do not depend only on the chlorine present for they are maintained with radicles other than chlorine, e.g. acetate, phosphate, nitrate. The nature of the organic radicle is of great importance. Although more study is required, it is our view that aliphatic organo-metallic compounds are more toxic than aromatic compounds. Such compounds are, however, very sensitive to water, e.g. Lewisite, methyl and ethyl arsine dichloride- $\left(\mathrm{CH}_{3}\right) \mathrm{AsCl}_{2}, \mathrm{C}_{2} \mathrm{H}_{5} \cdot \mathrm{As} \mathrm{Cl}_{2}$. The chlorine atom attached to the arsenic is very sensitive to water and is readily hydrolysed by it. For this reason the cyano derivative was a principal subject of study since it (a solid) is stable to and insoluble in water. This compound, one of the 'nose-irritant 'smokes,' has, however, diminished vesicant effects in comparison with the chlorcompounds.

It seems justified to say that the chlorine atom increases the vesicant action, and that the oily compounds are more active than the solid compounds. But it must not be supposed that solid compounds cannot be powerful vesicants (vide infra organic mercury compounds). Oil solubility is an impor- tant accessory property for vesicant action as opposed to water solubility.

\section{Organic Mercurial Compounds}

Considerable medical interest attaches to organic mercurial compounds. Hunter et al. (1940) have described in detail clinical and pathological effects which were produced in workers engaged in the preparation of methyl mercuric nitrate $\left(\mathrm{CH}_{3}-\mathrm{Hg}-\mathrm{NO}_{3}\right)$ and in monkeys exposed to the vapour. They also made short reference to the effects which compounds of this type could produce on the skin.

The development of organic mercury compounds for the protection of seed against attack by fungi constitutes an extremely interesting field in the scientific methods of plant protection and has contributed in vast degree to the increase of yield of a considerable number of different crops.

A large number of preparations containing organic mercury compounds has been marketed in various countries under a more or less confusing variety of names. It is often difficult to determine what the constituents of these products are. The object of all such preparations is to make possible a destruction or inhibition of growth of fungi which, if allowed to act on the seed, produce diseases in the plant leading to serious diminutions in the yield and, by offering them a satisfactory nidus for growth and multiplication, maintain the infectivity of the soil. This goal must be attained without injuring the seed, tuber or bulb or the process of germination. There are many techniques of attack on and defence against fungi and insects in the soil. Among these are the chemical treatment of the soil itself or of the seed, tuber or bulb. The particular chemical compounds used naturally depends upon their ascertained or claimed efficacy against particular insects or fungi known to attack crops in which the consumer is interested. They may be used in steeps, sprays, powders or dusts and it is both in the manufacture of the insecticide or fungicide and in its diluted applied form that medical hazard arises.

In greater or lesser measure all mercurial compounds are hazardous. Having regard, however, to the very large quantities used in agricultural and horticultural practice and the relatively small numbers of cases of toxic effects met with, it may be concluded that if the directions of the makers and distributors are followed no great anxiety need be felt in the utilization of most organic mercurials.

Most organic mercurials of the general formula $\mathbf{R}-\mathbf{H g}-\mathbf{R}^{\prime}$ where $\mathbf{R}$ may be a hydrocarbon (aromatic or aliphatic), a chlor-phenol, a cresyl or tolyl residue, a nitrophenol, and $\mathbf{R}^{\prime}$ an organic or inorganic anion (e.g. $-\mathrm{CN},-\mathrm{SO}_{4} \mathrm{Na},-\mathrm{OH}$, $-\mathrm{H}_{2} \mathrm{PO}_{4},-\mathrm{OCOCH}_{3}, \mathrm{Cl}$, etc.) are vesicants and it is of the effects of some of these that record is made in what follows.

Used in the form of dusts diluted with an inert powder the mercury contents of different preparations vary considerably but modifications are 
frequently made and marketed under the same name. Thus, Uspulun (Tillantin R) of probable formula

and Ceresan<smiles>O=[N+]([O-])C1CCC(O)CC1</smiles><smiles>CC(=O)OCC1CCCCC1</smiles>

both German preparations, were at one time marketed in dilutions containing 3.4 per cent. and 1.5 per cent. $\mathrm{Hg}$, respectively, but at a later date a new Ceresan appeared which was an entirely different compound, viz. methoxy-ethyl mercurinaphtha-sultam

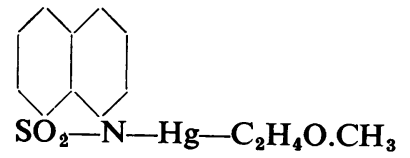

which, in the diluted form for use, contained 1.2 per cent. Hg. Agrosan, a British product, contains<smiles>CC(=O)OCC1CCCCC1</smiles>

probably a mixture of isomers and is marketed containing 1.5 per cent. $\mathrm{Hg}$, whereas a Ceresan made in Germany for the U.S.A. market contained 2.0 per cent. $\mathrm{Hg}$. The matter is complicated further by the fact that proprietary preparations contain more than one mercurial.

Attempts have been made to relate mercury content and molecular structure with fungicidal activity. Some evidence that increase in the molecular weight of $\mathbf{R}$ decreases fungicidal properties has been obtained but other factors than this enter and complicate the problem of practical application. Similarly, the content of mercury, important as it must surely be, is not readily to be regarded as determining fungicidal activity. The actual buildup of the molecule has great significance. As to the vesicant and dermatitic effects of these compounds, it is unfortunately the case that the users of this kind of compound are not as conscious of the need to apply the measures of protection seriously recommended by the manufacturers and always appear to have heard of these for the first time when workers are adversely affected. The fact is that of the preparations which ultimately reach the market in quantity, none will affect more than a minute fraction of persons using them if proper precautions are applied. From time to time, one sees reports of agricultural workers being burnt by seed dressed with mercurial compounds. A report appeared that a man had lost his life through ' having his hand burnt by mercurial salts while sowing a field of wheat, (Farmer and Studbreeder, 1943). No details are given about this case, but we should venture to doubt whether the 'mercurial salts' were indeed the cause of death.

The author had an opportunity to attend an inquest on a farm worker when it was alleged that his handling of seed dressed with mercurial compounds had contributed to his death. The cause of death in this case was septicaemia following an injury contracted during an attack on a rat in a farm shed.

Poisoning of farm animals and poultry is sometimes reported as resulting from the ingestion of grain dressed with mercurial fungicides. Thus, Edwards (1942) reports the case of a bay gelding of 16 hands, aged 9 years, which the owner stated had eaten a quantity of oats dressed with a mercurial, the quantity being ' not more than a quarter of a bucketful.' Edwards reports that the condition of the horse was that of advanced mercury poisoning - ' loose bowels,' anorexia, depression, dejected appearance, unsteady gait, increase in rate of pulse and of respiration, temperature $104^{\circ} \mathrm{F}$. Gangrene of the lungs was evident from the foetid sweetish breath coupled with a bloody, muco-purulent nasal discharge. The horse was dead next morning. Edwards notes the very small quantity of treated oats which suffices to poison so large an animal. Edwards also refers to fowls being poisoned from eating grain treated with mercurials. Such events in human subjects have not, as far as we know, ever been reported.

Apart, however, from the effects of these compounds as systemic poisons, there is need to consider their action on the skin since their widespread application brings cases to the notice of industrial and other medical men which may present difficulties both in diagnosis and treatment. The cases we describe occurred both in the use of such compounds already diluted with inert powders in agricultural work and in the mixing of them with diluents in works conditions.

Case 9. Case of handling dressed seed. F., 31 years old. Intelligent, healthy young farmer. Fair hair and skin.

In October, 1941, he was sowing seed in the course of which he had carried on his back sacks of seed dressed with a mercurial containing tolyl mercuric acetate. Twelve months prior to this he had observed a mild skin eruption during a similar operation, but this had passed off without much trouble. The present rash, however, was much more extensive. It consisted of 'spots' on his chest, back, groins and arms but not on his face and hands. The rash was not itchy.

His doctor diagnosed scabies and prescribed hot soda baths, scrubbing of skin and Proscabin. This resulted in the most maddening irritation and itching which became progressively worse. A consultant saw the condition and diagnosed it as eczema-dermatitis and treatment with Proscabin was stopped. The legs now began to swell and the condition became so bad that morphia was given and on some occasions the patient had to be tied down to the bed. A consulting dermatologist now saw the case and took him into hospital where he remained for 13 to 14 weeks. Every kind of blood and other tests were performed. X-ray therapy, at first not very successful, later apparently led to great improvement ( 3 or 4 exposures at intervals of $7-10$ days) with diminution of irritation and gain in sleep. A patch test with the mercurial seed dressing (details not known) gave an erythematous reaction. (A control test on another man led to blister formation. A medical officer at the hospital also applied the preparation to his own skin and reported intense irritation.) During the course of hospital treatment there was extensive exfoliation of the skin which, in the patient's own words, came off ' in buckets.' 
In September, 1942, patient left the hospital much improved and returned to light work, avoiding all contact with mercurials. Some 3 weeks afterwards he observed a reappearance of the condition and now, in addition to the former areas, the hands and face were also affected but in less degree. On examination at this stage by the writer it was found that in the axillae, umbilical region, belt line, anal cleft, buttocks, the skin was purple-red in colour, cracked, peeling and in the axillary. and pectoral regions intensely lichenified. The back and arms were less severely affected with many small vesicles at all stages of development. The dorsa of the hands were covered with minute vesicles. The legs and ankles were covered with an angry eruption of small vesicles at all stages.

\section{Diagnosis and Comment}

The condition when first seen by the writer was that of a severe chronic generalized inflammation of the skin, showing all the stages associated with a sensitization dermatosis. Some areas were obviously in the stage of acute exacerbation. The course of events point strongly to the original eruption having been due to the chemical irritant, but that the mistaken diagnosis of scabies and the violent treatment which followed it led to a condition of sensitization dermatosis. The latter continued for the long period described and recurrent exacerbations were to be expected. The fact that recurrence occurred without further exposure to the original irritant indicates that the sensitivity was now polyvalent. Whilst the vagaries of human skin do not permit us to rule out a polyvalent sensitivity from the original irritant, it is a fact that eruptions from organic mercurials are not characterized by the establishment of such a sensitivity if properly treated from the outset.

Case 10. Case during dressing of seed. M., 23 years old, fair haired, very healthy looking man.

This man was engaged in the actual dressing of seed with the mercury compound (containing tolyl mercuric acetate). He had done similar work in 1937 and 1938. In 1941, he resumed this kind of work. One day he noticed some non-itching, non-irritant blistering between the fingers of his right hand: 'the skin seems to just curl up and come away.' He also developed an eruption on the anterior neck; this started as a red patch and now appears as a localized group of broken-down vesicles. The condition was diagnosed by his doctor as ringworm and treated as such. The treatment made the eruption much worse and when seen by the writer he was being treated by ultra-violet irradiation.

\section{Diagnosis and Comment}

As in the former case, the doctor's diagnosis was certainly incorrect and due probably to lack of acquaintance with the effects of organic mercurials. The treatment would certainly involve the risk of establishing a sensitivity as in the former case.

Case 11. Case during dressing of seed. P. Not seen by writer.

This man was a soldier who had been released from the Forces to do seed-dressing work. After a week's work on seed dressing he developed blisters on his hands and had to leave work. The blisters were described as big ones, tense with fluid. It appears that the seeddressing machine had become partly blocked with paper and stringy material; $P$. put his bare hand into the machine to clear the obstruction and it became contaminated with the seed-dressing preparation. The skin blistering followed in a few hours. The further course is not known.

Examination of the seed-dressing plant at which Cases 10 and 11 had worked showed the reddish dust of the mercurial in considerable amounts strewn about the apparatus and the floor. At one point there was continued egress of the powder during the running of the machine. In spite of the warning instructions issued to the seed dressers, personal precautions were very poor.
The manager of the unit in spite of his skin already being affected, handled the preparation with the bare hands with the utmost unconcern. The bags containing the dressed seed were satisfactorily dust proof, a point of considerable importance since otherwise the mercurial dressing tends to 'bloom' out on to the outer surface of the bags.

Whereas the complaint met with among a small proportion of persons coming into contact with this mercurial compound is one of irritation of the skin, occasionally other symptoms are mentioned.

Case 12. Case during dressing of seed. Firm $H$.

Here men engaged in dressing seed with a mercurial had formerly complained only of skin irritation similar to that of cases described above. But it was reported that a recent consignment of the preparation had led to sickness, diarrhoea and loss of appetite, in addition to sneezing which, it was stated, was less pronounced than with previous batches of the material. This last statement is indubitable evidence of dissemination of the powder in the working place and indicates a gross neglect of the precautions emphasized by the makers.

Case 13. Case during dressing of seed. Firm S.

Here a man who had been in charge of seed dressing with a mercurial for several seasons without any skin affection found, subsequently, after some weeks of such work that the skin of his hands began to peel between the fingers and his eyes became irritated and painful.

Case 14. Case during dressing of seed. C. H., 22 years old, strong, healthy man, brunet type. No history suggestive of skin allergy.

He was transferred from field work to assist in seed dressing and dressing operations in a granary. The machine used was of a standard type and elementary precautions were taken to prevent dissemination of mercurial dust in the working place. He was engaged in filling sacks with dressed seed from the seed-dressing machine. Whilst the filling of the sack proceeds (4 bushels) he steps outside the immediate area of the sack, which is surrounded with fabric screens. When it is judged that the required weight of seed has entered, the man steps forward and shuts off the flow of grain, shakes the bag down, puts the bag on the weighing machine and adjusts the weight with a scoop. The bag is now tied and removed to a convenient spot.

After 9 hours of this work on the first day of his work in seed dressing he had dealt with 46 bags of grain. Having washed with cold water and soap, he went home without any complaint of skin irritation or discomfort. Next morning on waking his hands were blistered. He was sent to hospital where he was diagnosed as ' suffering from injury in the nature of a superficial skin burn associated with using a chemical seed dressing.' He was healed as an out-patient. The lesions were washed with ether and treated with picric acid. Progress was good.

The only subjective symptom complained of in the early stages was a sensation of heat some 12 hours after ceasing work. At no time was there complaint of pain and the patient slept through the night without discomfort whilst the lesion was developing.

When seen by the writer the superficial blistered skin had been removed from the fingers of both hands and the subjacent tissue was pink, healthily epithelializing, clean and dry. No other signs or symptoms were or had been present and recovery from the skin condition was uneventful. Recovery took about a month. The patient had been warned by the doctor never to undertake seed dressing again.

It is important to note that neither this man nor any of the others engaged in seed dressing wore protective garments of any kind. None of the other men had, however, suffered in any way from their contact with the seed-dressing material. The affected man had hot and perspiring hands to which, he stated, the powder tended to stick. 
The cases above described were due to dressing or handling dressed seed with a preparation containing totyl mercuric acetate. These were all men meeting the material during its agricultural application. Men engaged in the actual manufacture of organic mercurials are so guarded against contact by the nature of the plant that it is uncommon to come across a case of vesication. Opportunity has, however, presented itself to observe the effects of two other organic mercurials, phenyl mercury acetate and ethyl mercury phosphate.

\section{Case 15. Phenyl mercuric acetate-}

$$
\mathrm{C}_{6} \mathrm{H}_{5}-\mathrm{Hg}-\mathrm{O} . \mathrm{CO} \mathrm{CH}_{3} \text {. }
$$

G. S., aged 40 years. Process worker.

This man was engaged in grinding phenyl mercuric acetate in an experimental plant where the rigid precautions necessary in dealing with such compounds had not yet been introduced in the design of the plant itself. The worker wore tightly fitting rubber gloves but appears at some stage of his work to have got some of the powder into the gloves without noticing it. No immediate symptoms were experienced, but some hours later on washing his hands he noticed redness of the skin and experienced a burning sensation. Next day there were large bullae on the dorsa of both hands and on the medial and lateral surfaces of the fingers (see fig. 9).

As the case was seen with the extensive blisters intact, the opportunity was takcn to draw off some of the blister fluid with a hypodermic needle The fluid was straw coloured and coagulated in the tube yielding a serum in which analysis showed a content of $12 \mu \mathrm{g} \mathrm{Hg}$ per g. On making an incision into the raised skin, the subjacent layer could be seen as a jelly-like mass extruding into the incised area. This mass was clearly coagulating plasma from which, on slight pressure, serum could be expressed.

Treatment with sterile olive oil and bandages led to uneventful recovery in 22 days after the usual cracking and peeling of skin had taken place. Throughout the treatment there was no irritation or sepsis.

There can be no doubt that in this case the compound was in undiluted form and in extremely intimate contact with the skin. Nevertheless, no immediate symptoms were produced, vascular dilation and vesication following after a considerable delay.

The $\mathrm{Hg}$ demonstrated in the blister fluid is unequivocal proof of the penetration of the compound through the skin.

In a recent paper (McCord, Meck and Neal, 1941), the effects of phenyl mercuric oleate (commercial)

$\left(\mathrm{C}_{6} \mathrm{H}_{5}-\mathrm{Hg}-\mathrm{O} . \mathrm{CO} .\left(\mathrm{CH}_{2}\right)_{7}-\mathrm{CH}=\mathrm{CH}-\left(\mathrm{CH}_{2}\right)_{7}-\mathrm{CH}_{3}\right.$ on human and animal skin are described. These authors found that 0.5 per cent. of this compound in a mixture of paraffin oil, kerosene and acetone applied to human skin produced pain in 3 hours, great discomfort in 7 hours and in 20 hours vesication with an inflammatory areola. Control with the solvents produced no vesication but kerosene led to a definite inflammatory reaction after 24 hours. Whilst all persons tested with 0.5 per cent. and a high proportion of persons tested with 0.2 per cent. reacted in this way, no subject tested reacted to 0.1 per cent. Rabbit skin seemed more susceptible than human skin, $0 \cdot 1$ per cent. producing an inflammatory reaction. No further details are given of the reaction of animal skin, but we presume that vesication was not induced.

$$
\begin{aligned}
& \text { Case 16. Ethyl mercuric phosphate- } \\
& \qquad \mathrm{C}_{2} \mathrm{H}_{5}-\mathrm{Hg}-\mathrm{O}-\mathrm{P}(\mathrm{OH})_{2} \\
& \|_{0}
\end{aligned}
$$

This compound, like phenyl mercuric oleate, is used as a wood preserving agent. Vintinner (1940) describes the process of immersion of pine boards in a solution containing 1 part of ethyl mercuric phosphate in 6600 parts of water Men exposing their skin to the solution developed a burning sensation from 3 hours to 3 days after contact and this was followed by oedema and vesication. The vesicles were thick walled and taut and up to $1 \frac{1}{2}$ inches in diameter. Lesions appeared on hands, forearms and feet; in one case a vesicle appeared on the lower lip. Disability lasted for from 5 to $\mathbf{3 0}$ days. The author had record of 42 cases of this kind, but it appeared that some men were not susceptible.

The preparation used to make up the preserving solution consisted of 6.25 per cent. ethyl mercuric phosphate in borax and talc as diluents.

The kind of lesions produced by this mercurial is shown in a case of our own (fig. 10). The patient was a fair-haired and fair-skinned lad of 17 years. He was a laboratory assistant engaged in the preparation of a mixture of ethyl mercuric phosphate with inert diluents in a ball mill for research purposes. He wore rubber gloves with the sleeves of his overall tucked into them. $\mathrm{He}$ also wore a nose pad. Contamination of the hand with the mixture nevertheless occurred and led to the usual sequence of absence of initial symptoms, several hours later a sensation of heat and irritation with appearance of erythema and still later the advent of vesicles and blisters. The figure shows thick-walled vesicles on the palm and a denuded blister on a finger tip laying bare the subjacent tissue. After the blister had become established, no pain or irritation was experienced and the condition was readily healed without scar formation on the lines laid down above.

\section{Comments on the Handling of Mercurial Fungicides}

Including the references in the literature we now have evidence of the vesicant action of-

phenyl mercuric acetate,

ethyl mercuric phosphate,

phenyl mercuric oleate,

tolyl mercuric acetate.

It seems not unreasonable to anticipate that all compounds of this kind, i.e. of the type $\mathrm{R}-\mathrm{Hg}-\mathrm{R}^{\prime}$ would, in greater or less measure, have similar effects on the human skin.

From our observations on Case 15 we conclude that these compounds are demonstrably absorbed through the skin and that the degree of absorption is increased by maintained contact, particularly if trapped inside a glove.

The circumstances in which skin effects may occur have been indicated. The actual planting of dressed seed is almost universally done by machine drilling and, hence, handling is minimized. The dressing of the seed is properly done in specially adapted machines, but the possibility of contamination by and even inhalation of dust is not eliminated. Seed-dressing stations are not in general characterized by the installations required to maintain a dust-free atmosphere. It is not likely that seeddressing firms would look favourably on the need to set up plant assuring full protection of the workers and, hence, are likely to prefer to continue with such measures as gloves, overalls and, in some degree, warnings. It must be admitted that, if we judge by the relative numbers of cases brought to notice, the problem appears to a considerable extent to be under control. If proper attention is paid to prevent dissemination of mercurial dust and the workers wear an efficient dust mask or respirator, there should be little danger of systemic absorption. The protection of the skin is a more difficult matter. Non-fatty skin creams may have a function; even 
powdering the skin with inert powders before and during work may be useful. Gloves, if used, should be of stout fabric and designed to extend well up the arm. These should be washed daily and worn during all operations involving dressing seed, handling bags of dressed seed, making up the weights of bags of seed, loading, unloading, cleansing of machines and so on. Men on this kind of work should, ideally, wear overalls with the trouser legs over top-boots. There should be facilities at hand to permit of washing away contaminations of the skin as soon as they occur. Wrongly treated, the skin lesions may be followed by sensitization, but this need not occur if the cause of the condition is realized. As with most organic compounds some persons are inherently sensitive to any degree of contact.

Although we have not come across any case of systemic poisoning from these compounds in their agricultural use, it could be considered desirable to examine the urine of workers for $\mathrm{Hg}$ at specified intervals. Even in the manufacture of organic mercurials under the most stringent plant precautions, it is nevertheless possible to detect $\mathrm{Hg}$ in the urine although hitherto we have not detected clinical signs or symptoms of toxic absorption.

\section{E. Organic Thioisocyanates}

The vesicant action of allyl thioisocyanate (allyl mustard oil) is well known. The alkyl thioisocyanates are often referred to as a class as mustard oils.

The following properties are noteworthy:

$\mathrm{CH}_{2}=\mathrm{CH}-\mathrm{CH}_{2} \cdot \mathrm{N}: \mathrm{C}: \mathrm{S}$, allyl thioisocyanate, liquid, pungent odour, b.p. $151^{\circ} \mathrm{C}$.

$\mathrm{C}_{2} \mathrm{H}_{5} . \mathrm{N}: \mathrm{C}: \mathrm{S}$, ethyl thioisocyanate, liquid, pungent, b.p. $134^{\circ} \mathrm{C}$.

$\mathrm{CH}_{3} . \mathrm{N}: \mathrm{C}: \mathrm{S}$, methyl thioisocyanate, solid, m.p. $35^{\circ} \mathrm{C}$., b.p. $119^{\circ} \mathrm{C}$.

Organic thioisocyanates differ from the isomeric thiocyanates in that the alkyl radical is attached to the nitrogen atom thus:

$\mathrm{R}-\mathrm{N}=\mathrm{C}=\mathrm{S}$-thioisocyanate.

$\mathrm{R}-\mathrm{S}-\mathrm{C} \equiv \mathrm{N}$-thiocyanate.

The thioisocyanates have application in certain organic syntheses and are all powerful vesicants.

The following case is described first because it illustrates the characteristic action of this group of compounds and also because of the establishment of an extreme sensitivity after apparent cure.

Case 17. R. C. H., aged 18 years, student chemist.

This young man was engaged in a study of methods for the preparation of thioisocyanates.

1 st contact. Whilst reacting isopropylamine with carbon disulphide in caustic soda followed by decomposition with basic lead acetate for the preparation of isopropyl thioisocyanate $\left(\left(\mathrm{CH}_{3}\right)_{2} \mathrm{CH}\right.$.NCS $)$, he experienced some slight irritation of the skin but this soon passed off.

2nd contact. A few days later prepared methyl thioisocyanate by same reaction using methylamine instead of isopropylamine and decomposing with ethyl chloroformate instead of basic lead acetate. On this occasion there was pronounced irritation and lachrymation (due to the chloroformate). This also passed off quickly.

$3 r d$ contact. One month after the first contact was again preparing $\mathrm{CH}_{3} \mathrm{NCS}$ and whilst washing his apparatus noticed slight lachrymation and irritation of the fingers. The latter became worse next day and there developed small, medium-sized hard vesicles on the palms and fingers; the fingers became oedematous and there was slight itching; small vesicles appeared on left flexor forearm and left neck which cleared up in a day or two. The subsequent development on the hands; however, was severe. All work was discontinued.

Days
after 3 rd
contact

contact

3 Confluence of vesicles with production of massive blisters involving the whole thickness of the palmar skin. No pain or itching. Fingers very oedematous with appearance of fresh blisters. Some of the thin-walled blisters on the interphalangeal surfaces oozing (fig. 11).

8 Many vesicles have drained spontaneously; considerable desquamation; oedema of hands much diminished; skin, mainly of palmar surface of fingers, stippled with irregular spots.

11 Blisters are now mainly hard lumps; skin cracking in parts with slight bleeding; at finger tips one feels, on pressure, the separation of whole thickness of skin from subjacent layers; affected parts are discoloured to brown; stippling has now gone from parts where skin is now hard and ready to detach.

14 Skin of whole affected part now thick, hard, cracked and peeling. It is clear that the whole of the palmar skin will be lost. Subjacent tissue pink, clean and dry.

15 Pain on extending fingers. Hard blistered skin slowly separating.

28 Progressive improvement maintained. Skin of hands now appears almost normal but somewhat mottled.

Thus, in about a month there had been complete detachment of the entire palmar skin of both hands and re-establishment of apparent normality. Treatment had been on the lines already described and there seemed no reason to anticipate further difficulty. Patient was, however, not permitted to recommence work in organic research.

Nevertheless, some 7 days later, the patient, on entering the laboratory for some hours where work on thioisocyanates was proceeding, developed an exacerbation of the skin of the palms of both hands. The skin became itchy, hot, swollen and tight and massive blisters developed on palm and fingers. Treatment was required for 14 days.

The importance of this case lies mainly in the extreme sensitivity which remained after the initial severe vesication had completely disappeared, for the second attack occurred without any manifest contact with the original vesicant except the slight concentration of vapour in the atmosphere of the laboratory. It seems clear that even slight concentrations of vapour can penetrate the skin and evoke (directly or indirectly) increased vascular permeability, which is a necessary prelude to vesicle formation, in cases of extreme sensitivity such as that described above.

This case re-emphasizes the need for extreme caution when deciding on the return to chemical work after an attack of severe vesication. : The same caution is, indeed, required after any severe attack of skin inflammation due to chemical irritants.

The nature of this caution is :

(a) To be assured that the skin is completely restored to, at any rate, apparent normality;

(b) to permit return to work at first without any exposure to chemical irritants, in order to 
ascertain whether the mere act of work is supported by the skin;

(c) to permit later return to work with compounds other than that which brought about the original attack, in order to determine whether a polyvalent sensitivity has become established:

(d) to permit later return to original work first more or less as an onlooker and, if no exacerbation occurs, as a full participant with precaution.

Proceeding in such a way may, perhaps, be regarded as an attempt at desensitization and in a considerable number of cases success is attained but many cases, in spite of long delay before return to normal work, retain an untractable sensitivity and must be transferred to non-chemical work. We have seen cases maintaining hypersensitivity twenty years after the original attack by a particular compound.

It is not our purpose to discuss the question of idiosyncratic sensitivities but one further case may perhaps be of interest as showing a high degree of sensitivity to compounds which ordinarily do not act as vesicants.

Case 18. McK. Process worker. Poor physical condition.

This man had worked in an experimental chemical plant for 5 days preparing diphenylacetophenone $\left(\mathrm{C}_{6} \mathrm{H}_{5} \mathrm{COCH}\left(\mathrm{C}_{6} \mathrm{H}_{5}\right)_{2}\right.$. In the ordinary routine of the plant he wore gauntlet gloves but being inexperienced he turned the gauntlets down and some material from the reaction mixture entered and remained in close contact with the skin of his right hand and lower forearm.

Diphenylacetophenone is formed by the condensation of benzoin $\left(\mathrm{C}_{6} \mathrm{H}_{5} \mathrm{CHOH} . \mathrm{CO} . \mathrm{C}_{6} \mathrm{H}_{5}\right)$ with benzene in presence of concentrated sulphuric acid which removes the elements of water.

The phenomena which followed on the worker's skin render it certain that there was no contamination with the concentrated acid and we attribute them to the solution of benzoin in benzene.

Pain was not felt at the time of the contamination but was experienced on going home at end of day's work. This was followed by development of oedema and erythema of the right hand and wrist and severe vesication. The blisters were, as usual, tense with yellow plasma and an area where a strap was worn remained pale and unaffected (figs. 12 and 13).

The course was uneventful but somewhat protracted.

In attributing the case to sensitivity to the benzene- benzoin mixture we do not ignore the fact that there was extreme intimacy of contact for several hours. We have never seen blistering from either of these compounds but were not able to perform suitable tests on the patient. Benzoin is a powerful reducing agent, reducing Fehling in the cold, a fact which may be related to the effect described.

\section{Summary}

A short description of the possible mechanism of vesication is given.

A technique for treatment of chemical vesication is described.

Certain compounds met with in the organic chemical industry which are powerful vesicants are considered. These are:

derivatives of pyrimidine,

derivatives of alkyl sulphides,

derivatives of arsine,

organic mercurial compounds,

organic thioisocyanates.

The establishment of hypersensitivity to chemical compounds after the apparent healing of a vesicated skin is a frequent event and special precaution is required in deciding on the return to work of the affected person. In certain cases photosensitivity may follow vesication.

\section{REFERENCES}

Colebrook, L., et al. (1944). Studies of Burns and Scalds. M.R.C. Spec. Rep Ser No. 249.

Edwards, C. M. (1942). Vet. Records, 54, 5.

Haas, H. T. A. (1941). Arch. f. exp. Path. u. Pharmak, 197, 161 Hunter, D. Bomford, R. R., Russeli, D. S. (1940). Ouart. J. Med.

9ewis, T. (1927). The Blood Vessels of the Human Skin and their Responses. Shaw \& Sons, London.

Logie, N.J. (1944). Lancet, 2, 138.

McCord, C. P., Meck, S. F., and Neal, T. A. (1941). J. industr. Hyg., $23,466$.

MacLeod, J. M. H., and Muende, I. (1940). Pathology of the Skin. H. K. Lewis, London.

Maximow, A. A., and Bloom, W. (1934). Textbook of Histology. W. B. Saunders, Philadelphia and London.

Medical Manual of Chemical Warfare (1940). H.M.S.O., Lond.

Moss, J. (1942). N. Carolina med. J., 3, 243.

News Item (1943). Farmer and Studbreeder. 20th July.

Vintinner, F. J. (1940). J. industr. Hyg., 22, 297. 